\title{
Sustainability in Software Engineering: A Systematic Literature Review
}

\author{
Birgit Penzenstadler, Veronika Bauer \\ Technische Universität München, Germany \\ \{penzenst|bauerv\}@in.tum.de
}

\author{
Coral Calero \\ Universidad de Castilla - La Mancha, Spain \\ Coral.Calero@uclm.es
}

\author{
Xavier Franch \\ Universitat Politècnica de Catalunya, Spain \\ franch@essi.upc.edu
}

\begin{abstract}
Background: Supporting sustainability in software engineering is becoming an active area of research. We want to contribute the first Systematic Literature Review(SLR) in this field to aid researchers who are motivated to contribute to that topic by providing a body of knowledge as starting point, because we know from own experience, this search can be tedious and time consuming.

Aim: We aim to provide an overview of different aspects of sustainability in software engineering research with regard to research activity, investigated topics, identified limitations, proposed approaches, used methods, available studies, and considered domains.

Method: The applied method is a SLR in five reliable and commonly-used databases according to the (quasi-standard) protocol by Kitchenham et al. [1]. We assessed the 100 first results of each database ordered by relevance with respect to the search query.

Results: Of 500 classified publications, we regard 96 as relevant for our research questions. We sketch a taxonomy of their topics and domains, and provide lists of used methods and proposed approaches. Most of the excluded publications were ruled out because of an unfitting usage of terms within the search query.

Conclusions: Currently, there is little research coverage on the different aspects of sustainability in software engineering while other disciplines are already more active. Future work includes extending the study by reviewing a higher number of publications, including dedicated journal and workshop searches, and snowballing.
\end{abstract}

\section{Motivation AND BACKGROUND}

Sustainability is currently an omni-present term in calls for research proposals and conference sessions (ICSE, CAiSE, RE, etc.). However, in literature, there is no overview of the current state of the art in supporting sustainability in software engineering research and practice. Consequently, researchers who are motivated to contribute to that topic (like the first author [2]) have to invest much time in finding a basic body of knowledge through literature research of many unrelated leads.

This paper reports on our systematic literature review with the objective of retrieving a solid basis of knowledge ${ }^{1}$ on the support of sustainability in software engineering. The full protocol is available online as technical report [4].

${ }^{1}$ One of the common motivators for SLRs named by Zhang and Babar in [3 Tab.I].

\section{A. Definition of Sustainability}

To clarify our research objective, we define our understanding of sustainability and what we mean by sustainability and how we want to apply it to software engineering. The most cited definition of sustainable development [5] is to "meet the needs of the present without compromising the ability of future generations to satisfy their own needs." According to [5], sustainable development needs to satisfy the requirements of the three dimensions of society, economy, and environment. A fourth dimension, human sustainability, is less present in the public discussion. According to [6], it should be included, as it is the basis for the other dimensions. All four dimensions of sustainability are further detailed on in our SLR protocol [4].

\section{B. Sustainability Aspects in Software Engineering}

Sustainability aspects can be brought to bear both during the development and use of software systems. We distinguish four aspects of sustainability in SE (orthogonal to the dimensions introduced in Sec. I-A. The development process viewpoint includes:

- Development process aspect: Sustainability in the initial system development process (with responsible use of ecological, human, and financial resources). This aspect focusses on the initial conceptual and constructional development and we distinguish it from the late phase of actual system production for reasons of analysis.

- Maintenance process aspect: Sustainability of the software system during its maintenance period until replacement by a new system (with continuous monitoring of quality, knowledge management).

The product viewpoint encompasses the aspects of sustainability during production and usage:

- System production aspect: Sustainability of the software system as product with respect to its use of resources for production (using green IT principles and sustainably produced hardware components). The actual system production happens after most of the initial development process and considers, inter alia, mass production aspects, logistics and factory organization issues. 
- System usage aspect: Sustainability in the usage processes in the application domain triggered by the software system as product (responsible in impact on environment, using green business processes).

We expect these aspects to have different scales of impact, growing from small to large in the order presented above, so that the system usage aspect potentially has the biggest impact (and, therefore, improvement potential). However, this is also dependent of the system under analysis.

For our SLR, we are looking for all four aspects of sustainability in software engineering. The aspects imply different levels of abstraction and varied granularity, but nevertheless we are interested in the state of research for each of them.

\section{A Body of Knowledge for Sustainability in SE}

Our research aim for the next years is to support the development of ICT systems for environmental sustainability (ICT4ES) with an adequate software engineering approach that integrates the knowledge of related disciplines that are concerned with sustainability. For that we need to build up on existing knowledge is SE as well as disciplines that have been related closer to sustainability, for example, environmental informatics.

This research aim requires accumulating a body of knowledge for various reasons: justifying the basis for future research, learning as much as possible from other domains related to the topic, and providing a basis for other researchers as well as students who consider learning about and contributing to this area. One commonly accepted research method for accumulating a body of knowledge is a study in form of a systematic literature review [3].

\section{Research Questions}

The overall research objective of the study is to find out what the current state of the art in supporting sustainability in software engineering research and practice is. This is further detailed in the following research questions:

RQ1 How much activity was there in the last 20 years?

RQ2 What research topics are being addressed?

RQ3 What are the limitations of current research?

RQ4 How is sustainability support performed?

RQ5 Which methods are in use?

RQ6 Are there case studies available?

RQ7 Which domains are already considered?

\section{E. Related Work}

There are systematic literature reviews on different topics in software engineering, but so far none has been conducted that investigates the relation between sustainability and software engineering.

\footnotetext{
${ }^{2}$ Our hypothesis is that most publications will be much younger, so a time span of 20 years ensures that we include all relevant ones.
}

Mahaux et al. [7] performed a preliminary search on the DBLP Computer Science Bibliography databas ${ }^{3}$ For articles with the prefixes "sustainab-" OR "ecolog-" OR "environmental-" in the title, the data base returned over 3000 results (in January 2010), but filtering on important software-related venues lead to as few as 11 results. They propose that a systematic literature review should be conducted.

In contrast to [7], we are interested in publications from all scientifically sound venues and journals as we see great potential for learning from other domains. Therefore, we did not restrict this systematic literature review to softwarerelated venues, which is the main reason why we received more results.

\section{SeArch Design AND PRocess}

The search design and procedure follow the guidelines in [1]. As SLR research questions we directly adopted those enumerated in Sec. II-D The search process for this study is based on an automated search of the following digital libraries:

- IEEE Digital Library http://ieeexplore.ieee.org

- ACM Digital Library http://dl.acm.org

- SpringerLink www.springerlink.com

- ScienceDirect / Scopus http://www.sciencedirect.com

- Web of science http://apps.webofknowledge.com/WOS

\section{A. Search String}

The aim for our search string is to capture all results that relate sustainability or environmental issues with software engineering or requirements for software systems. The reasons for searching for requirements is that in this early development phase sustainability issues should emerge. The search string used on all databases is:

(sustainab* OR environment* OR ecolog* OR green) AND

(software engineering OR requirement OR software system)

Although we explicitly list keywords in our search string that rather point to environmental sustainability, we expect to find all dimensions of sustainability.

\section{B. Inclusion Criteria}

We chose the following inclusion criteria in order to select the relevant publications to answer our research questions:

- Publication date between 1/1/1991 - 31/12/2011

- Requirements phase of software development process

- Explicit mentioning of software engineering

- Scientific soundness

- Relevance with respect to research questions

- Analysis of sustainability-relevant application domains

- Coverage of a SW ecosystem or SW sustainability

http://dblp.mpi-inf.mpg.de/dblp-mirror/index.php 


\section{Exclusion Criteria}

- "Environment" used in the sense of system environment, not nature.

- "Ecosystem" used as population of interacting systems, for example, agents.

\section{Roles and Responsibilities}

- Birgit Penzenstadler (TUM, principal researcher): IEEEXplore, result classification, detailed analysis

- Zolboo Ochirsukh, Elena Mircheva, Duc Tien Vu, Tuan Duc Nguyen (TUM, student research assistants): search on ACM, Web of Science, ScienceDirect, SpringerLink

- Veronika Bauer (TUM, expert reviewer): assessment of search result classification, review of detailed analysis

- Coral Calero (UCLM, expert reviewer): assessment of search result classification and detailed analysis

- Xavier Franch (UPC, expert reviewer): review of detailed analysis

\section{E. Article Selection Process}

The process was conducted as follows:

1) The researchers execute the search on each database and save the references in bibliography files.

2) The principal researcher reads all titles and abstracts and checks the inclusion and exclusion criteria for each entry. Major criterion is the topic of the content.

3) The principal researcher classifies the papers and articles according to type, topic, and domain.

4) The expert reviewers reassess the classification and inclusion/exclusion of search results. After their reassessment, we introduce an additional result classification: domain-specific papers that are interesting to learn from but not focussed on software engineering.

5) The principal researcher extracts statistics and analyses the included results in further detail. This is followed by a second assessment from the expert reviewers.

\section{F. Data Analysis}

The data is tabulated to show:

- The databases and numbers of query results. (RQ1)

- Listed by database for included publications:

- Author, reference, date (RQ1)

- Publication type and type of content (RQ6)

- Topic of content (RQ2, RQ4, RQ5)

- Application domain (RQ7)

- Benefit for our body of knowledge (RQ4)

- The number of relevant publications per year. (RQ1)

- The respective venues and journals. (RQ1)

Furthermore, the findings for RQ3, RQ4 and RQ5 are reported on separately. Due to the limitation of space, we provide the full list of references of the primary study as online appendix [8].

\section{RESULTS}

The overall number of results for each data base is listed in Tab. I

Table I

Number of RESUlts PER DATABASE

\begin{tabular}{l|l|l}
\hline Database & Date & Results \\
\hline \hline IEEE Xplore & $27 / 12 / 11$ & 319.601 \\
ACM Digital Library & $26 / 12 / 11$ & 104.217 \\
SpringerLink & $29 / 12 / 11$ & 500.004 \\
ScienceDirect / Scopus & $29 / 12 / 11$ & 10.749 \\
Web of Science & $29 / 12 / 11$ & 80.503 \\
\hline
\end{tabular}

All results were ordered "by relevance" as displayed by the databases. From these results, we considered the first 100 results of each data base in our first iteration of the study. In total, we reviewed 500 publications.

The following abbreviations are used to categorize the results in Tab. II

- Publication: Kind of publication, e.g., Journal Article (A), Conference Paper (CP), Workshop Paper (WP), Book Chapter (BC), Letter to the editor (L)

- Type: Kind of content presented in the publication, e.g., method, experience report, empirical study, tool

- Topic: Short hint on principal content and keywords of the paper or article

- Domain: Application or technology domain considered in the publication, e.g. transport, aviation, embedded systems, information systems, human aspects

- Benefit: Classification of why we consider this publication to be relevant with respect to the research questions: Sustainability in software engineering ( $S$ in $S E$ ), sustainability-related application domains ( $S A p p$ Dom), sustainability (modeling) concept (S Concept), sustainable software solutions ( $S W$ Sol), sustainable hardware solutions ( $\mathrm{S} \mathrm{HW} \mathrm{Sol}$ )

RQ1: How much activity was there in the last 20 years?

We summarized the number of relevant publications per database in Tab. VII per year in Tab. VIII and per publication type in Tab. IX. In the last two years, there was a significant increase in the number of publications, and there was no publication included that was older than 2005, so our hypothesis for RQ1 holds. None of the results we included are older than 2005, but we did have older search results in the query evaluations, so this is not due to restricted availability online. Although we executed the search queries in late December, we already found journal articles dated to January 2012 in the results which we included as they were fully available.

While the venues were relatively distributed, there was an accumulation of publications from "Environmental Modeling \& Software" as well as the "Journal of Cleaner Production". The fact that we classified many of the publications as "software solutions" or "sustainability-related application 
Table II

INCLUDED RESULTS FROM IEEE XPLORE, FULL REFERENCES IN APPENDIX [8]

\begin{tabular}{|l|l|l|l|l|l|l|}
\hline Author and reference & Date & Pub. & Type & Topic & Domain & Benefit \\
\hline \hline Kung et al. & 2011 & CP & method & green decision-making framework & building construction & S App Dom \\
Middendorf et al. & 2009 & CP & method & envir. aspect in mechatronics design & mechatronics, robots & S App Dom \\
Ulieru & 2010 & CP & method & design for resilience of networked critical infrastructures & digital eccsystems & S App Dom \\
Albertao et al. & 2010 & CP & metrics & sustainability performance of software & eBusiness & S Concept \\
Zhou et al. & 2008 & CP & method & green remanufacturing engineering in structural machinery & security tech. & S App Dom \\
\hline
\end{tabular}

Table III

INCLUDED RESULTS FROM ACM, FULL REFERENCES IN APPENDIX [8]

\begin{tabular}{|c|c|c|c|c|c|c|}
\hline Author and reference & Date & Pub. & Type & Topic & Domain & Benefit \\
\hline Mouton et al. & 2009 & $\overline{\mathrm{A}}$ & model & habitat suitability models for river management & ecological knowledge & S App Dom \\
\hline Geist et al. & 2009 & a & challenges & computer science challenges at exascale & high performance computing & S SW Sol \\
\hline O'Sullivan & 2010 & $\mathrm{CP}$ & method & ta mining for biodiversity prediction in forests & forestry, data mining & S App Dom \\
\hline Penzenstadler et al. & 2011 & $\mathrm{CP}$ & method & teach sustainability in software engineering & education & $\mathrm{S}$ in $\mathrm{SE}$ \\
\hline Zhongjia et al. & 2010 & $\mathrm{CP}$ & prototype & design of self-propelled walking brush cutter & digital manufacturing & S HW Sol \\
\hline Audisio et al. & 2009 & A & method & hazard management in two Alpine river basins & GIS tool & S App Dom \\
\hline Miginsky et al. & 2008 & A & method & mputer reconstruction of the biological networks & ecological networks & S SW Sol \\
\hline Pennington et al. & 2008 & A & method & indirectly driven knowledge modeling in ecology & knowledge models & S Concept \\
\hline Blevis et al. & 2007 & $\mathrm{CP}$ & reflectio & design critique as research to link sustainability and interactive technologies & design research & S Concept \\
\hline Adomavicius e & 2007 & A & model & chnology roles \& influence in an ecosystem model of technology evol. & technology ecosystem & S Concept \\
\hline Pereira et al. & 2009 & A & method & knowledge discovery for coastal waters classification & environmental monitoring & S SW Sol \\
\hline Henriksen et al. & 2007 & A & method & public participation modeling in management of groundwater contamination & groundwater management & $\mathrm{s}$ conc \\
\hline Dick et al. & 2011 & $\mathrm{CP}$ & model & meta-design environments to motivate changes in energy consumption & energy sustainability & S SW Sol \\
\hline Ticehurst et al. & 2007 & A & model & assessing the sustainability of coastal lakes & environmental management & S Concept \\
\hline Shih et al. & 2010 & A & model & butterfly and wetland ecology for context-aware ubiquitous learning & mobile learning & S App Dom \\
\hline Cushing et al. & 2007 & A & method & database design for ecologists & ecosystem info management & S SW Sol \\
\hline Cushing et al. & 2006 & $\mathrm{CP}$ & overvieu & eco-informatics and natural resource management & eco-informatics & S Concept \\
\hline Kang et al. & 2008 & A & method & GIS-based poultry litter management system for nutrient planning & decision support & S App Dom \\
\hline Amsel et al. & 2010 & $\mathrm{CP}$ & tool & tool for estimating the energy consum & green computing & S SW Sol \\
\hline Choucri et al. & 2011 & WP & model & simulation modeling approach to evaluate renewable energy readiness & energy simulation & S App Dom \\
\hline Vicat-Blanc et al. & 2011 & $\mathrm{BC}$ & model & optical networks and cloud as architecture for a sust. future internet & cloud & S App Dom \\
\hline DesAutels et al. & 2011 & A & model & explore the market price of "sustainable" notebooks & life cycle analysis & S App Dom \\
\hline Ramona & 2009 & $\mathrm{CP}$ & method & consolidating eco-economics through financial and fiscal instruments & eco-culture & S Concept \\
\hline Mathevet & 2007 & A & & role-playing game for collective awareness of wise reedbed use & environmental education & S App Dom \\
\hline Salski & 2007 & $\mathrm{CP}$ & method & 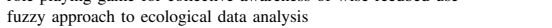 & fuzzy systems & S Concept \\
\hline Abidin et al. & 2010 & A & tool & tool to detect and predict urban growth pattern & neural network & S App Dom \\
\hline Kase et al. & 2008 & $\mathrm{CP}$ & mode & sustainable informal it learning in community-based nonprofits & education & S Concept \\
\hline Prabhakar et al. & 2010 & A & model & transfer scheme for energy harvested WSN gateways & energy grids & S App Dom \\
\hline Umstatter & 2011 & A & review & review of the evolution of virtual fences & electronics in agriculture & S App Dom \\
\hline Vance & 2007 & $\mathrm{CP}$ & model & permanent coexistence for a linear response omnivory model & modeling & S App Dom \\
\hline Pousman & 2008 & $\mathrm{CP}$ & method & casual information visualization of printer data & sustainability design & S SW Sol \\
\hline Fu et al. & 2011 & $\mathrm{CP}$ & framework & urban media framework of social innovation and service design & service design & S Concept \\
\hline
\end{tabular}

Table IV

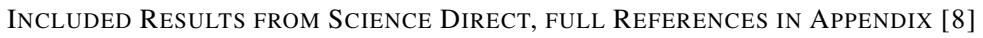

\begin{tabular}{|c|c|c|c|c|c|c|}
\hline Author and reference & Date & Pub. & Type & Topic & Domain & Benefit \\
\hline Abdulaziz et al. & 2011 & A & revien & car parking requirements for sustainable transport development & transport & S App Dom \\
\hline Alain et al. & 06 & A & hod & modeling living systems, their diversity and their complexity & gronomy systems & S App Dom \\
\hline Alexandrov & 11 & $\mathrm{~L}$ & sessment & technical assessment and evaluation of environmental models & environmental modeling & S Concept \\
\hline Ashraf et al. & 2012 & A & method & image data fusion for the remote sensing of freshwater environments & applied geography & S App Dom \\
\hline Beusen et al. & 2011 & A & & dynamic simulation and visualization software for mathematical models & environmental modeling & S SW Sol \\
\hline Bovea et al. & 2012 & A & tool review & taxonomy of ecodesign tools for integrating environmental requirements & clean production & $\mathrm{S}$ in $\mathrm{SE}$ \\
\hline Brown et al. & 2010 & A & & software tool designed to verify ensemble forecasts of numeric variables & environmental modeling & S SW Sol \\
\hline Cardona et al. & 2011 & A & model & software package developed for dynamic simulation of water quality in rivers & environmental modeling & S SW Sol \\
\hline & & 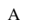 & metho & management-oriented valuation for ecol. water requirements for wetlands & & S App Dom \\
\hline Faith-Ell et al. & 2006 & A & case study & application of environmental requirements in Swedish road maintenance contracts & cleaner production & S App Dom \\
\hline Fan et al. & 2007 & A & model & model for China's energy requirements and $\mathrm{CO} 2$ emissions analysis & energy & S App Dom \\
\hline & 2006 & 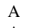 & & software package for optimi & y protection & S SW Sol \\
\hline Harmon & 2009 & A & evaluation & exploratory evaluation of the market case for green energy & green energy & S App Dom \\
\hline Hughes et al. & 2010 & A & framework & determination of environmental water requirements for rivers & environmental modeling & S App Dom \\
\hline Justyna et & 2010 & A & review & green roof performance towards management of runoff water quantity and quality & ecological engineering & S App Dom \\
\hline Kalivara & 2008 & A & framework & software framework for modeling of contaminant transport in groundwater & environmental modeling & S SW Sol \\
\hline Kit et al. & 2012 & A & & texture-based identification of urban slums in India using sensing data & applied geography & S SW Sol \\
\hline Koormann et al. & 2006 & A & model & modeling down-the-drain chemicals in rivers & environmental modeling & S Concept \\
\hline Kubba & 201 & $\mathrm{BC}$ & 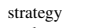 & green proj & architecture & S Concept \\
\hline Liu et al. & 2011 & A & study & energy requirements and carbon dioxide emissions of tourism industry & energy & S App Dom \\
\hline Mei et al. & 2010 & A & review & research progress of ecological water requirement in china & ecological informatics & S App Dom \\
\hline Naumann et al & 2011 & A & model & reference model for green and sustainable software and its engineering & software engineering & $\mathrm{S}$ in $\mathrm{SE}$ \\
\hline Rizzo et al. & 2006 & A & evaluatior & dynamic systems-based software packages for ecological systems & environmental modeling & S SW Sol \\
\hline Smith et al. & 2010 & $\mathrm{CP}$ & method & green product design through product modularization using atomic theory & lean manufacturing & S Concept \\
\hline Tong et al. & 2011 & A & method & generating the plan of mandatory green space in urban systems & urban development & S App Dom \\
\hline Tseng et al. & 201 & A & study & evaluating a firm's green supply chain management & cleaner production & S App Dom \\
\hline $\mathrm{Xu}$ et al. & 201 & A & review & review on ecological engineering based engineering management & management & S Concept \\
\hline Yen et al. & 2011 & A & study & management's role in adopting green purchasing standards in industry & business research & S Concept \\
\hline Zhang et al. & 2011 & A & study & costs and barriers of green property development in China & property development & S App Dom \\
\hline Zhang et al. & 2010 & A & model & multi-source remote sensing data for estimating ecological water require & environmental modeling & S SW Sol \\
\hline
\end{tabular}

Table V

INCLUDED RESUlTS FROM SPRINGER LINK, FULL REFERENCES IN APPENDIX [8]

\begin{tabular}{|l|l|l|l|l|l|l|}
\hline Author and reference & Date & Pub. & Type & Topic & Domain & Benefit \\
\hline \hline Huang et al. & 2009 & CP & study & support green customers' decision process on electronic commerce & web engineering & S App Dom \\
Liao et al. & 2009 & CP & method & multimedia stream format and green design concept for e-learning & education & S Concept \\
Liu et al. & 2008 & A & method & wheat growth model multi-agent system & computing in agriculture & S SW Sol \\
Du & 2010 & A & method & neural network control for greenhouse management & computing in agriculture & S SW Sol \\
May et al. & 2006 & CP & method & composing biological workflows through web services & parallel processing & S SW Sol \\
\hline
\end{tabular}


Table VI

InCluded RESUlts From Web Of SCIENCE, Full REFERENCES IN APPENDiX [8]

\begin{tabular}{|c|c|c|c|c|c|c|}
\hline Author and reference & Date & Pub. & Type & Topic & Domain & Benefit \\
\hline Alvarez et al. & 2011 & A & method & 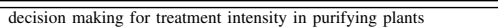 & wastewater & 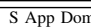 \\
\hline Balana et al. & 2011 & A & review & cost-effectiveness analysis of agri-environmental measures & water pollution & S App Don \\
\hline Boose et al. & 2007 & $\mathrm{CP}$ & method & reliable datasets for environmental models with an analytic web & ecological data sets & S SW Sol \\
\hline Bravi et al. & 2011 & A & assessment & life cycle assessment of a micromorph photovoltaic system & energy & S App Don \\
\hline Ellison et al. & 2006 & A & model & analytic webs support the synthesis of ecological data sets & ecological data sets & S SW Sol \\
\hline Greene et al. & 2010 & A & method & decision analysis with exploration and evaluation phases & land management & S App Dom \\
\hline Hall et al. & 2011 & A & method & requirements for $3 \mathrm{D}$ vegetation structure from space & environmental modeling & S SW Sol \\
\hline I-Wah & 2011 & A & analysis & development and conditions of home-school cooperation & education & S Concept \\
\hline Jia et al. & 2011 & A & case study & urban wetland planning in Beijing & ecological complexity & S App Don \\
\hline Jin et al. & 2011 & A & study & integrated calculation of ecological water demand for & water demand & S App Don \\
\hline Kaduk et al. & 2011 & A & method & redicting the time of green up in temperate and boreal biomes & climate change & S App Dom \\
\hline Lundy et al. & 2011 & A & method & integrating sciences to sustain urban ecosystem services & geography & S Concept \\
\hline McCabe & 2006 & A & overviev & sustainable building design in Australia & eco-architecture & S App Don \\
\hline McIntosh et al. & 2007 & A & method & database design for ecologists including observation data & ecoinformatics & S SW Sol \\
\hline Scheller et al. & 2010 & A & method & increasing the reliability of ecological models using $\mathrm{SE}$ techniques & software engineering & $\mathrm{S}$ in $\mathrm{SE}$ \\
\hline Seppala et al. & 2011 & 管 & 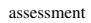 & greenhouse a emissions and & clean production & S App Dom \\
\hline Singh et al & 2011 & A & method & resource conservation technology in rice-wheat cropping system & environment & S App Don \\
\hline Tao et al. & 2008 & $\mathrm{CP}$ & model & UML-based green alignment selection decision making model & intelligent computation & $S$ in SE \\
\hline Verweij et al. & 2010 & A & perspective & IT perspective on integrated environmental modeling & software engineering & $\mathrm{S}$ in $\mathrm{SE}$ \\
\hline Wang et al. & 2008 & $\mathrm{CP}$ & meth & trol of & cost con & S Conce \\
\hline Wang et al. & 2009 & $\mathrm{CP}$ & & web-based distributed certification system of green food & env. science & S SW Sol \\
\hline Xu et al. & 2007 & A & evalua & sustainability evaluation of a nature reserve project & environmental manag & S App Don \\
\hline Zhang et al. & 2011 & A & assessment & combine hiostabilization and londfill for solid wat & environmental mana & S App Don \\
\hline Zhou et al. & 2008 & $\mathrm{CP}$ & method & green remanufacturing engineering in structural machinery & security technology & S App Don \\
\hline
\end{tabular}

domain", some more as "sustainability concepts" and only few as "sustainability in software engineering" implies that there is still relatively little research published that could be considered for building up a body of knowledge.

Table VII

INCLUDED RESULTS PER DATABASE

\begin{tabular}{|l|r|}
\hline Name & Number of Included Results \\
\hline \hline IEEEXplore & 5 out of 100 \\
ACM Digital Library & 32 out of 100 \\
Springer Link & 5 out of 100 \\
Science Direct & 30 out of 100 \\
Web of Science & 24 out of 100 \\
\hline Total & 96 out of 500 \\
\hline
\end{tabular}

Table VIII INCLUDED RESULTS PER YEAR

\begin{tabular}{|l|r|}
\hline Year & Number of Results \\
\hline \hline $1991-2005$ & 0 \\
2006 & 9 \\
2007 & 12 \\
2008 & 11 \\
2009 & 11 \\
2010 & 21 \\
2011 & 29 \\
2012 & 3 \\
\hline Total & 96 \\
\hline
\end{tabular}

Table IX

InCluded Results PER Publication Type

\begin{tabular}{|l|r|}
\hline Publication Type & Number of Results \\
\hline \hline Journal articles & 65 \\
Book chapters & 2 \\
Conference papers & 27 \\
Workshop papers & 1 \\
Letters to the editor & 1 \\
Technical reports & 0 \\
\hline Total & 96 \\
\hline
\end{tabular}

\section{RQ2: What research topics are being addressed?}

For a quick illustrated overview, we have generated a weighted topic cloud from keywords, taken from the titles and abstracts, that visualizes the topics in Fig. 1. We have derived a taxonomy for the addressed research topics in Fig. 2 that abstracts from some of the details listed in the original classifications tables in Tab. III $\mid \mathrm{VI}$. The dimensions of the taxonomy are the degree of domain specifity, from general purpose to domain-specific research and the indexing between analytical approaches (frameworks and assessment) and constructive approaches (methods and tools). The taxonomy shows a tendency towards domain-specific, constructive approaches. There are not many publications rated as general purpose, and there is little methodical guidance for supporting sustainability.

Both the keyword cloud and taxonomy rely strictly on keywords taken from titles and abstracts. Nevertheless, their reproduction might reveal slightly varied results, but we do not consider that a problem as we use them only to give an overview of topics without deriving any further statistics from them.

RQ3: What are the limitations of current research?

To identify limitations of current research, we reviewed our classification of topics and application domains in Tab. II VI. We performed a pragmatic and informal gap analysis that resulted in three major limitations:

- High complexity.

Reason: Due to the high connectivity between the different aspects of sustainability, (software) systems engineering becomes highly complex. This is visible in knowledge management approaches, e.g., [9] and decision support systems, e.g., [10].

Conclusion: High complexity requires clear concept definitions and consistent, traceable models. One method to cope with high system complexity that might prove helpful is systems' thinking [11]. 


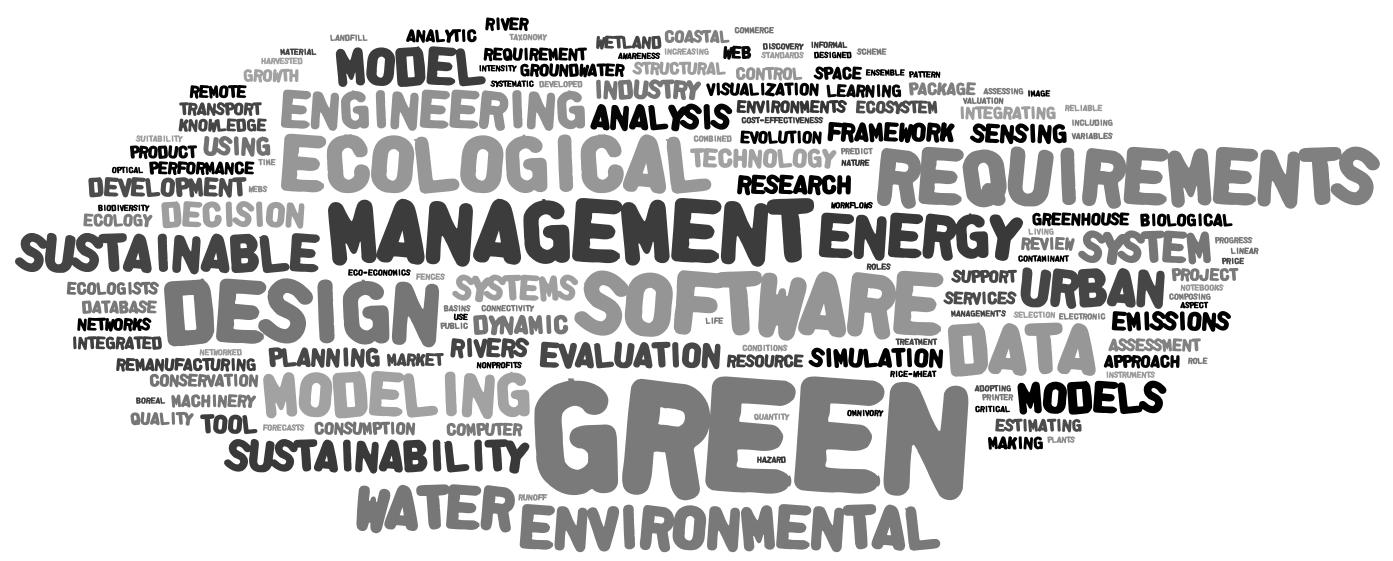

Figure 1. Weighted topic cloud, created with http://www.wordle.net/

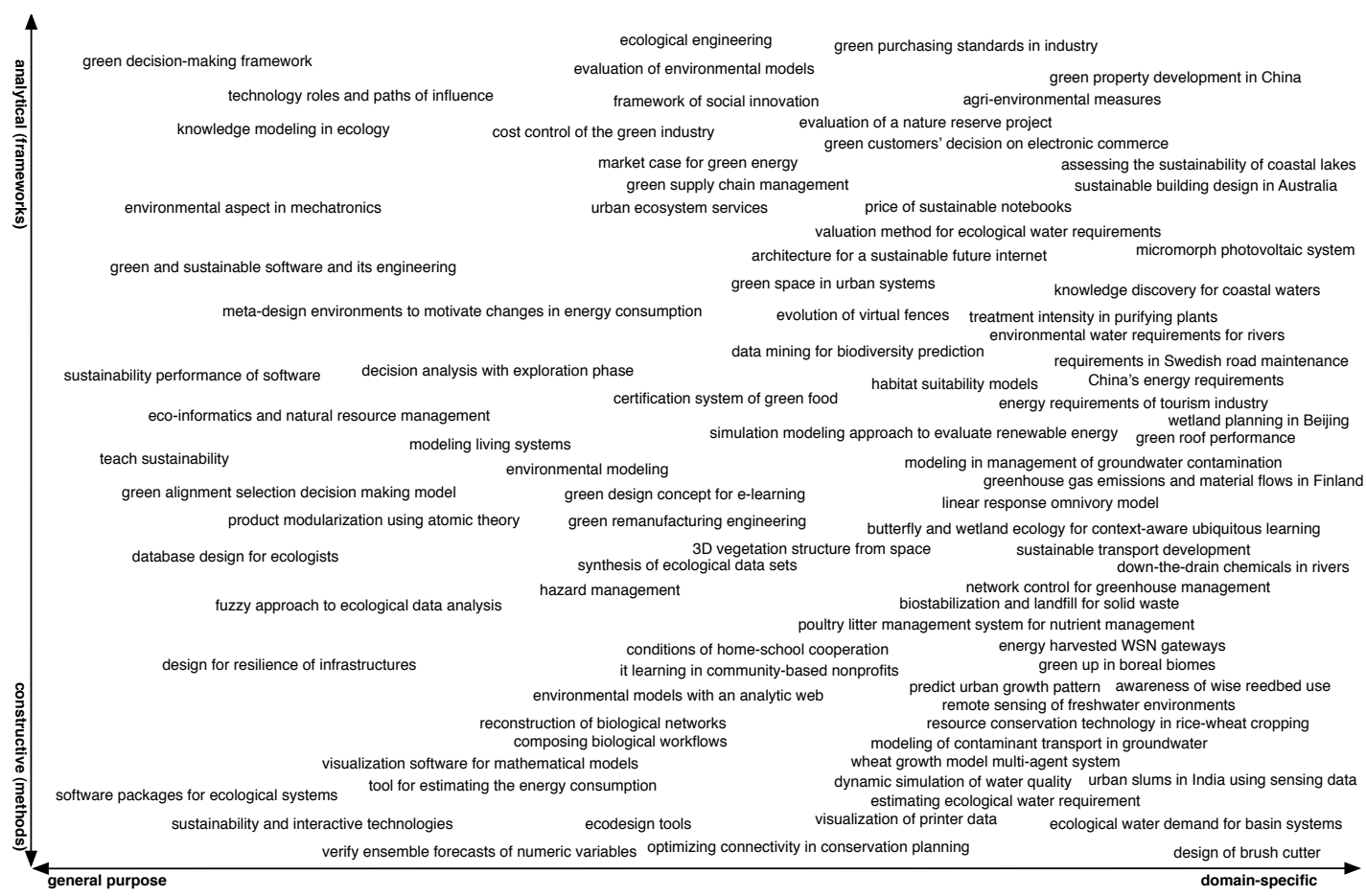

Figure 2. Taxonomy of research topics

- High domain-specifity.

Reason: The frameworks and methods we found within the results are highly domain-specific, e.g., [12], [13]. This is also visible in the higher density of domainspecific approaches in Fig. 2

Conclusion: Effective approaches for supporting sustainability require specific domain knowledge.

- Software engineering.

Reason: There is only one approach in software engineering that explicitly addresses sustainability. It is a reference framework with specific application in web engineering [14].

Conclusion: An encompassing reference framework for SE is still missing.

\section{RQ4: How is sustainability support performed?}

Constructive support for sustainability is performed by frameworks, models, methods, and metrics (Tab. X. Thereby, most approaches are specific to a special application domain, as visible by the density on the domain-specific side in Fig. 2 .

- Frameworks, e.g., for civil engineering [12] or contaminant transport [15] 
Table $\mathrm{X}$

INCLUDED RESULTS PER CONTENT TYPE

\begin{tabular}{|l|l|r|}
\hline Class & Type of Content & Number of Results \\
\hline \hline Constructive & Method & 36 \\
& Model & 18 \\
& Metrics & 1 \\
& Framework & 2 \\
& Tool/Prototype & 9 \\
\hline Empirical & Review & 6 \\
& Study & 8 \\
& Evaluation & 3 \\
& Assessment & 4 \\
\hline Discussion & Overview & 2 \\
& Challenges & 1 \\
& Analysis & 1 \\
& Reflection & 1 \\
& Perspective & 1 \\
& Strategy & 1 \\
\hline
\end{tabular}

- Models, e.g., for software systems [14] or databases [16]

- Methods for specific application areas, e.g., security technology [13], green product design [17], or ecology knowledge [9]

- Metrics, e.g., for sustainability in eBusiness [18]

We chose just a few of the approaches for illustration and preferred the ones that are rather close to sustainability in software engineering. Furthermore, there are some empirical publications and rather few discussions.

\section{RQ5: Which methods are in use?}

There is a wide variety of methods in use for different purposes - we found traditional software engineering techniques as well as domain-specific techniques and methods from other disciplines.

Many approaches apply entity-relationship modeling, e.g. [9], as means to represent their data, knowledge, or information models. Neural networks are in use for dynamic environments and simulations, e.g. [19]. Methods adapted from other disciplines are, inter alia, cost calculations, e.g. [20], and life cycle analysis, e.g. [21].

\section{RQ6: Are there case studies available?}

We classified publications as case studies when they were explicitly named as such in the abstract and they were not, for example, only containing a small illustrative case study within a method proposal. The studies are listed in Tab. XI. Unfortunately, none of the studies contributes explicitly to an understanding of how to develop software for sustainable systems, but rather to analyses of specific application domains. Furthermore, publications that promote studies are often method proposals illustrated in a case study performed by the principal researcher.

\section{RQ7: Which domains are already considered?}

For an illustrated overview, please see the weighted domain cloud that visualizes the application domains in Fig. 3 .
We have derived a taxonomy for the domains that were used and described in the publications in Fig. 4. We used the same dimensions as for the research topics taxonomy in Fig. 2 and identified five coarse-grained domain clusters: Systems \& Knowledge in the area of general purpose, analytical approaches, Technologies \& Methods on the constructive side of the general purpose dimension, Education somewhere in the middle between these two, special Disciplines provide more domain-specific, analytical approaches, and the corresponding Application \& Implementation cluster contributes the domain-specific, constructive approaches. These clusters are not overlap-free, but only a means to illustratively structure their diversity. The terms within the cluster clouds in Fig. 4 indicate the individual domains.

\section{Discussion}

This section provides a discussion of the results and of the threats to validity for this study.

\section{A. Conclusions on the State of the Art}

We started our search expecting to find more results to be classified as Sustainability in Software Engineering $(S$ in $S E$ in column Benefit in Tab. II VI. As we found less than expected for a body of knowledge on $S$ in $S E$, we decided to extend the inclusion to publications that we classified as a research we could learn from when further investigating sustainability in software engineering. This lead to the other Benefit categories S Concept, S App Dom, S SW Sol, and S $H W$ Sol as explained in Sec. III.

In our opinion, there is still a lot of research work to be done, especially to support the different dimensions of sustainability from within the software engineering discipline. This can either occur in form of domain-independent guidelines or domain-specific methods.

\section{B. Conclusions for a Body of Knowledge}

Due to these findings, our envisioned Body of Knowledge has areas that represent the core $S$ in $S E$ publications, plus areas that represent application domains with software and hardware solutions as well as sustainability concepts from related disciplines that we can learn from. This is illustrated in in Fig. 5

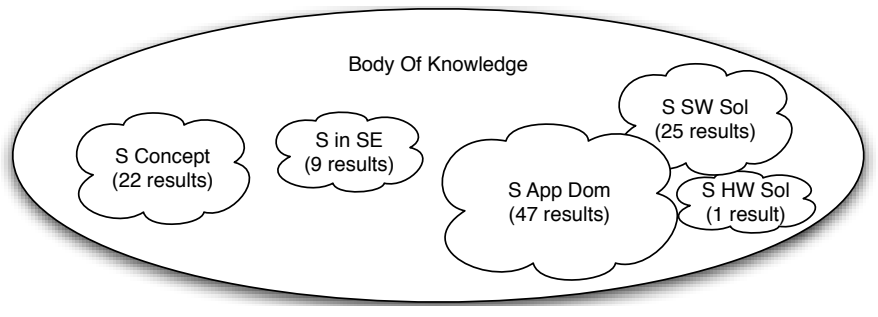

Figure 5. Areas of the Body of Knowledge for S in SE 
Table XI

Case Studies

\begin{tabular}{|c|c|c|c|}
\hline Author and ref. & Domain & Context & Applied method \\
\hline $\begin{array}{l}\text { Huang et al. [10] } \\
\text { Faith-Ell et al. [22] } \\
\text { Liu et al. [23] } \\
\text { Tseng et al. [24] } \\
\text { Yen et al. } 25 \\
\text { Zhang et al. [26], } 27 \\
\text { Jia et al. } 28 \\
\text { Jin et al. } 29\end{array}$ & $\begin{array}{l}\text { web engineering } \\
\text { cleaner production } \\
\text { energy } \\
\text { cleaner production } \\
\text { business research } \\
\text { property development } \\
\text { ecology } \\
\text { hydrology }\end{array}$ & $\begin{array}{l}\text { support green customers' decision process on electronic commerce } \\
\text { application of environmental requirements in Swedish road maintenance } \\
\text { energy requirements and carbon dioxide emissions of tourism industry } \\
\text { evaluating a firm's green supply chain management } \\
\text { management's role in adopting green purchasing standards in industry } \\
\text { costs and barriers of green property development in China } \\
\text { urban wetland planning in Beijing } \\
\text { ecological water demand for basin systems }\end{array}$ & $\begin{array}{l}\text { questionnaire and experiment } \\
\text { semi-structured interviews } \\
\text { index decomposition analysis } \\
\text { relational analysis, experiment } \\
\text { questionnaires } \\
\text { cost analysis } \\
\text { ecological complexity research } \\
\text { integrated calculation }\end{array}$ \\
\hline
\end{tabular}

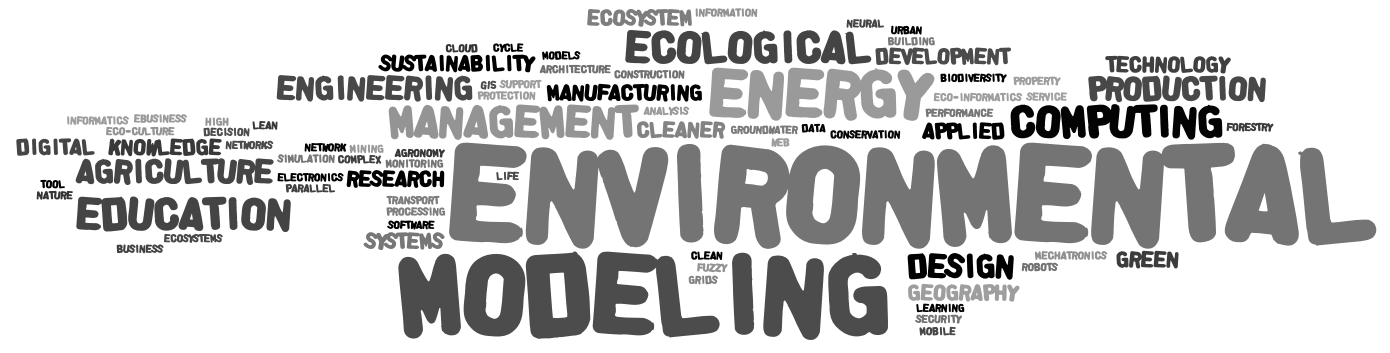

Figure 3. Weighted domain cloud, created with http://www.wordle.net/

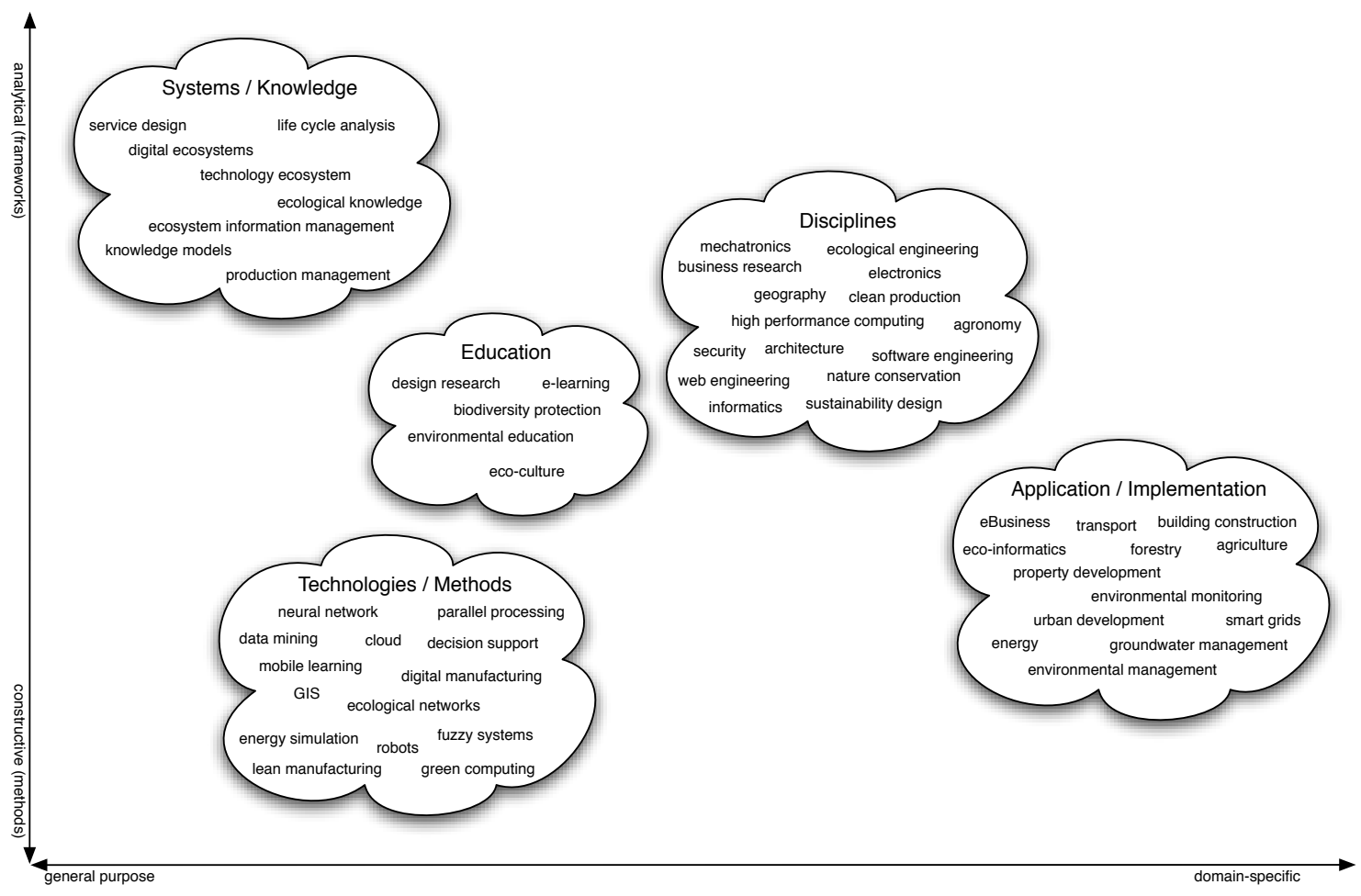

Figure 4. Taxonomy of application domains 


\section{Threats to Validity}

There is a number of threats to validity that we are aware of and tried to minimize by different mitigation actions.

1) Researcher's bias: The semi-automatic part of the search was performed by five researchers. There could be a researcher's bias as the first selection was performed by only one researcher. We minimized the effects of such a bias by two measures:

- We explicitly stated the research questions, inclusion and exclusion criteria, and the rationale for performing the search.

- The first selection was reviewed and assessed by two expert reviewers from different institutions (TUM, UCLM). Differences were subsequently discussed, resolved and commonly agreed upon.

- The detailed analysis of the principle researcher was reviewed by all three expert reviewers (TUM, UCLM, UPC).

2) Search string validity: The search string validity can be questioned under two aspects: On one hand whether it filtered out too many publications that would have been relevant, and on the other hand whether it included too many irrelevant results and was, in either case, not the adequate search string.

Indicators for too many false positives are purely hardware papers, but as the automatically found Green IT publications all contained part of the second parenthesis of the search string, they were included in the results. Then, purely application in environmental domains, for example, agricultural support systems with no explicit relation to sustainability but relevant in case they exhibited an explicit link to sustainability in their content. Furthermore, "environment" used in the sense of system environment, not nature - these samples had to be excluded by hand as well as "ecosystem" used as population of interacting systems, for example, agents.

Indicators for too many relevant exclusions were that we found less relevant results than we would have expected. This can either be due to a search string that was too restrictive, to a search that was not extensive enough, or to the fact that there is rather little published yet on that specific topic. Not all publications we would have expected showed up early in the search results. For example, we missed Cabot et al. [30], as they treat goal modeling for supporting sustainability in the context of conference organisation. Mahaux et al. [7] were also missing in the results, with their work on exploring sustainability requirements $4^{4}$

3) Database query evaluation: We did not have any information on which database performed which kind of search query evaluation, and a lazy versus an eager database query evaluation of the search string would probably have a

\footnotetext{
${ }^{4}$ These works were not included into the results manually because we wanted to strictly follow the SLR method. However, they will be included in the extended version and the envisioned body of knowledge.
}

significant impact on the search results, considering that we reviewed the first 100 most relevant results.

In case of a "lazy" search string evaluation, the results might have included more references matching early parts of the search string than compared to matching later parts. In that case, the results might be slightly biased in terms of favoring the terms "sustainab" and "software engineering" and subordinating "green" and "software systems".

As many of the results contained the term "software system" and not "software engineering", we are confident that there was no bias introduced by database query evaluation.

4) Cross-validation of the search engines: We received hardly any double entries in the automatic search results. We would have expected some double entries in the more general databases ScienceDirect and WebOfScience. We decided not to use meta search engines in our first iteration of the SLR because relying on only one meta search engine would have made us completely dependent of the reliability of that engine, and using various meta search engines would have led to highly redundant results, as a pre-check showed.

Interestingly, Web of Science found Estrin [31] highly ranked, which originates from IEEEXplore but was not included in the IEEEXplore results (at least not within the first 100 results). This might be a hint towards different search query evaluation.

It would be one interesting step in future work to replicate the searches on more databases and meta search engines and explicitly compare the coverage.

\section{CONCLUSions}

In this paper, we presented the results of our SLR [4] on the research activity in sustainability in software engineering and related topics that allow for building up a body of knowledge. We considered 96 of 500 reviewed publications relevant with respect to our research questions and classified them according to content, topic, application domain, and potential benefit for further investigation. On that basis, we provided taxonomies for represented research topics and application domains. As there were not as many publications explicitly presenting work on sustainability in software engineering than expected, we propose an extended body of knowledge for $S$ in $S E$ that includes related application domains and sustainability concepts from related disciplines that we can learn from when further investigating $S$ in $S E$.

Future work is to extend the study in two directions: on one hand by snowballing (following references) and on the other hand via meta search engines, book search engines, and dedicated journal searches. Probably even more important is the challenge of making SLRs themselves "sustainable" by providing yearly updates that not only repeat an SLR but adapt the iterations over the years according to lessons learned from previous iterations. Thereby, we can establish stable bodies of knowledge. 


\section{REFERENCES}

[1] B. Kitchenham and S. Charters, "Guidelines for performing systematic literature reviews in software engineering," tech. rep., Software Engineering Group, Keele University, 2007.

[2] B. Penzenstadler, B. Tomlinson, and D. Richardson, "Support environmental sustainability by requirements engineering," in International Workshop on Requirements Engineering for Sustainable Systems, 2012.

[3] H. Zhang and M. Babar, "An empirical investigation of systematic reviews in software engineering," in Empirical Software Engineering and Measurement (ESEM), 2011 International Symposium on, pp. 87 -96, sept. 2011.

[4] B. Penzenstadler, V. Bauer, and C. Calero, "Sustainability in software engineering: A systematic literature review for building up a knowledge base," tech. rep., Technische Universität München, 2012.

[5] United Nations World Commission on Environment and Development, "Report of the World Commission on Environment and Development: Our Common Future," in United Nations Conference on Environment and Development, 1987.

[6] R. Goodland, Encyclopedia of Global Environmental Change, ch. Sustainability: Human, Social, Economic and Environmental. John Wiley and Sons, 2002.

[7] M. Mahaux, P. Heymans, and G. Saval, "Discovering Sustainability Requirements: an Experience Report," in 17th International Working Conference on Requirements Engineering: Foundation for Software Quality, 2011.

[8] B. Penzenstadler, V. Bauer, C. Calero, and X. Franch, "Appendix: References of the Included Results of the SLR Sustainability in Software Engineering." http://www4.in.tum. de/ penzenst/sources/ease2012_slr_appendix.pdf

[9] D. D. Pennington, I. N. Athanasiadis, S. Bowers, S. Krivov, J. Madin, M. Schildhauer, and F. Villa, "Indirectly driven knowledge modelling in ecology," International Journal of Metadata, Semantics and Ontologies, Volume 3 Issue 3, 2008.

[10] F.-H. Huang, Y.-L. Lee, and S.-L. Hwang, "E-shopping behavior and user-web interaction for developing a useful green website," in Human-Computer Interaction. New Trends (J. Jacko, ed.), vol. 5610 of Lecture Notes in Computer Science, pp. 446-454, Springer Berlin / Heidelberg, 2009. Springer.

[11] D. Meadows, Thinking in Systems: A Primer. Chelsea Green Publishing, 2008.

[12] P. Kung, V. C. Chen, and A. Robinson, "Multivariate modeling for a multi-stage green building framework," in 2011 IEEE International Symposium on Sustainable Systems and Technology (ISSST), pp. 1-6, IEEE, May 2011.

[13] G. Zhou, G. Duan, H. Wu, and T. Yao, "Green remanufacturing engineering in structural machinery based on reverse engineering," in International Conference on Security Technology, 2008. SECTECH '08, pp. 221-225, IEEE, Dec. 2008.

[14] S. Naumann, M. Dick, E. Kern, and T. Johann, "The greensoft model: A reference model for green and sustainable software and its engineering," Sustainable Computing: Informatics and Systems, no. 0, pp. -, 2011.

[15] V. Kalivarapu and E. Winer, "A multi-fidelity software framework for interactive modeling of advective and diffusive contaminant transport in groundwater," Environmental Modelling \& Software, vol. 23, no. 12, pp. 1370 - 1383, 2008.

[16] J. B. Cushing, N. Nadkarni, M. Finch, A. Fiala, E. MurphyHill, L. Delcambre, and D. Maier, "Component-based enduser database design for ecologists," Journal of Intelligent Information Systems, Volume 29 Issue 1, 2007.
[17] S. Smith and C.-C. Yen, "Green product design through product modularization using atomic theory," Robotics and Computer-Integrated Manufacturing, vol. 26, no. 6, pp. 790 - 798, 2010. 19th International Conference on Flexible Automation and Intelligent Manufacturing: Lean manufacturing and Services.

[18] F. Albertao, J. Xiao, C. Tian, Y. Lu, K. Q. Zhang, and C. Liu, "Measuring the sustainability performance of software projects," in 2010 IEEE 7th International Conference on eBusiness Engineering (ICEBE), pp. 369-373, IEEE, Nov. 2010.

[19] L. Du, "Expert control based on neural networks for controlling greenhouse environment," in Computer and Computing Technologies in Agriculture III (D. Li and C. Zhao, eds.), vol. 317 of IFIP Advances in Information and Communication Technology, pp. 126-132, Springer Boston, 2010. Springer.

[20] C. Ramona, "Creating and consolidating eco-economics through financial and fiscal instruments. contribution of green taxes," Proceedings of the 8th WSEAS international conference on System science and simulation in engineering, 2009.

[21] M. Bravi, M. L. Parisi, E. Tiezzi, and R. Basosi, "Life cycle assessment of a micromorph photovoltaic system," Energy, vol. 36, pp. 4297-4306, July 2011.

[22] C. Faith-Ell, B. Balfors, and L. Folkeson, "The application of environmental requirements in swedish road maintenance contracts," Journal of Cleaner Production, vol. 14, no. 2, pp. 163 - 171, 2006.

[23] J. Liu, T. Feng, and X. Yang, "The energy requirements and carbon dioxide emissions of tourism industry of western china: A case of chengdu city," Renewable and Sustainable Energy Reviews, vol. 15, no. 6, pp. 2887 - 2894, 2011.

[24] M.-L. Tseng and A. S. Chiu, "Evaluating firm's green supply chain management in linguistic preferences," Journal of Cleaner Production, no. 0, pp. -, 2010.

[25] Y.-X. Yen and S.-Y. Yen, "Top-management's role in adopting green purchasing standards in high-tech industrial firms," Journal of Business Research, no. 0, pp. -, 2011.

[26] X. Zhang, A. Platten, and L. Shen, "Green property development practice in china: Costs and barriers," Building and Environment, vol. 46, no. 11, pp. 2153 - 2160, 2011.

[27] X. Zhang, L. Shen, and Y. Wu, "Green strategy for gaining competitive advantage in housing development: a china study," Journal of Cleaner Production, vol. 19, no. 2-3, pp. 157 - 167, 2011.

[28] H. F. Jia, H. T. Ma, and M. J. Wei, "Urban wetland planning: A case study in the beijing central region," Ecological Complexity, vol. 8, pp. 213-221, June 2011.

[29] X. Jin, D. H. Yan, H. Wang, C. Zhang, Y. Tang, G. Y. Yang, and L. H. Wang, "Study on integrated calculation of ecological water demand for basin system," Science Chinatechnological Sciences, vol. 54, pp. 2638-2648, Oct. 2011.

[30] J. Cabot, S. Easterbrook, J. Horkoff, L. Lessard, S. Liaskos, and J.-N. Mazon, "Integrating sustainability in decisionmaking processes: A modelling strategy," in Software Engineering - Companion Volume, 2009. ICSE-Companion 2009. 31st International Conference on, pp. 207 -210, May 2009.

[31] D. Estrin, "Participatory sensing: Applications and architecture," Ieee Internet Computing, vol. 14, pp. 12-14, Jan. 2010. 